\title{
Effect of in situ and laboratory compaction on the retention behaviour of a clayey soil
}

\author{
Francesca D'Onza ${ }^{1, a}$, Vincenzo Oliviero ${ }^{2}$, Domenico Gallipoli ${ }^{3}$, Claudio Mancuso ${ }^{2}$ and Simon J. Wheeler ${ }^{4}$ \\ ${ }^{1}$ ENEA, Infrastructures and Services Directorate, 80055 Piazzale E. Fermi, Portici, Italy \\ ${ }^{2}$ UNINA, Department of Civil, Architectural and Environmental Engineering, 80137 Via Claudio 21, Napoli, Italy \\ ${ }^{3}$ Université de Pau et des Pays de I'Adour, Laboratoire SIAME, France \\ ${ }^{4}$ University of Glasgow, School of Engineering, G12 8LT Oakfield Avenue, Glasgow, UK
}

\begin{abstract}
A clayey soil has been tested in the laboratory in order to investigate the influence of the compaction procedure on the soil retention behaviour. In common engineering practice, data available for modelling are those of the soil compacted in the laboratory and soil behaviour during the earth structures lifecycle is predicted on that basis. This practice, however, seems to overlook the fact that construction procedures in the field might differ significantly from the compaction techniques used in the laboratory and this may induce considerable differences in material texture and therefore in the soil behaviour. The investigation shown in the present work aims to provide further insight into this aspect and to help endorsing or refuting the validity of such practice.
\end{abstract}

\section{Introduction}

The engineering properties of compacted soils can be designed by controlling particle grading, compaction method, water content and plasticity $[1,2]$. This is very important for earth structures, which are almost invariably built by using locally sourced soils to minimize transportation costs and carbon footprint. If local soils show poor engineering characteristics, appropriate techniques must be used before and during emplacement of the fill to enhance mechanical performance through compaction. Although the behaviour of laboratory compacted soils is relatively well understood, there are still considerable uncertainties about the influence of field compaction techniques on soil properties. Further research in this respect is therefore required to maximize efficiency and cost-effectiveness of engineering design.

Earth embankments are usually built by compacting soils at the optimum water content as determined in the laboratory by means of a Standard Proctor test. Current geotechnical practice assumes that the energy applied to the soil during field compaction of earth embankments is comparable to that applied in the laboratory during Standard Proctor compaction. This means that the in-situ properties of earth fills are also similar to those of laboratory samples compacted at the same water content and according to the Standard Proctor method. Based on this assumption, laboratory compacted samples can be used to characterize the mechanical and water retention properties of earth fills.

This practice, however, overlooks the fact that field construction might differ significantly from laboratory

\footnotetext{
a Corresponding author: francesca.donza@enea.it
}

compaction and this can induce considerable differences in material texture and, hence, engineering properties between the two materials.

The present study aims to investigate this issue by testing the same soil compacted both in situ (according to usual field construction procedures) and in the laboratory (according to the Standard Proctor method). In particular, the paper focuses on the study of water retention, which is an essential aspect of soil behaviour for the prediction of the deformation, strength and permeability of engineering fills.

\section{Experimental apparatus and testing program}

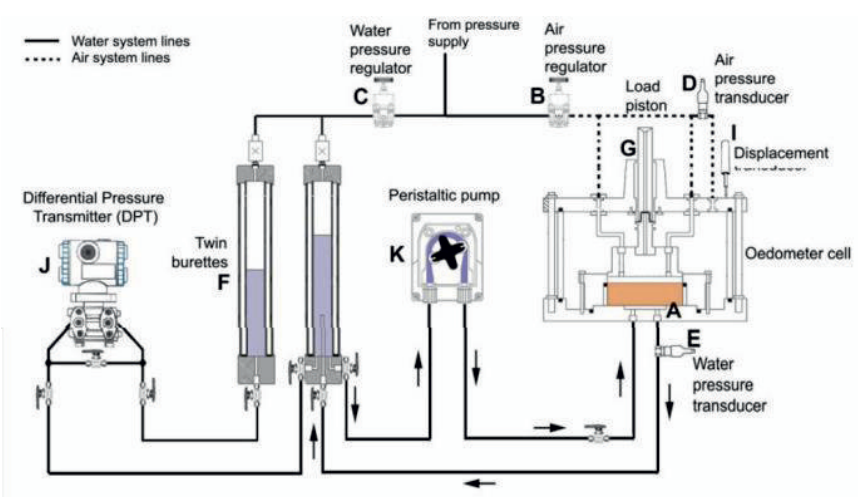

Figure 1. Wissa oedometer modified for testing unsaturated soils. 
The experimental apparatus used in this work is a Wissa oedometer that can accommodate specimens with a diameter of $79.8 \mathrm{~mm}$ and a height of $25 \mathrm{~mm}$ (Fig. 1).

As well as oedometric CRS tests, the apparatus allows running either constant net stress or constant volume suction controlled tests. A personal computer connected to a load cell and to a digital ram regulates the vertical stress level using a feed-back procedure. Only constant net stress tests are presented in this paper.

Suction is controlled by the axis translation technique. The pore water pressure is applied at the base of the specimen, while the pore air pressure is applied at the top. The high air entry value porous stone, which is placed between the base of specimen and the water drainage circuit, has an air entry value of $1500 \mathrm{kPa}$. Nevertheless, because of limitations to the maximum pressure achievable by the pore air supply, the largest applicable suction is only $850 \mathrm{kPa}$. The axial strains, and therefore the volumetric strains, are monitored by an external LVDT.

Water content changes are monitored by measuring the volume of water flowing in or out of the specimen through a measuring burette. The level inside the measuring burette is recorded by means of a differential pressure transducer connected to on the other side to a second burette with a constant water level used as a reference.

The saturation of the pore water line is ensured by periodically flushing the drainage circuit through a peristaltic pump ( $\mathrm{K}$ in figure 1 ) that pushes water through a spiral groove cut inside the base pedestal. This forces any potential air bubble into the measurement burette where it is eliminated by buoyancy through the free water surface. The arrows in Figure 1 show the flushing path.

A thin layer of silicon oil is placed upon the water surface in both measurement and reference burettes to keep evaporation losses within acceptable limits. In addition, any potential evaporation should be the same in both burettes due to the symmetry of the system.

Evaporative losses through the air drainage line cannot be predicted as they depend on several factors including sample water content, air humidity and pressure. These evaporative losses are therefore measured at the end of each suction equalization stage when the sample is assumed to be in equilibrium. At this point, all loss of water is attributed to air evaporation and is fitted by a linear relationship with time, which is then used for correcting water content measurements.

\section{Experimental procedure}

The soil tested in this work is a clayey silt from a flood defence embankment of the Po River (Italy). Basic soil properties such as Atterberg limits, specific gravity, and grain size distribution were determined on several samples.

The soil has a specific gravity equal to 2,740 , a uniformity coefficient, Uc, $\approx 15$, a clay fraction of about $25 \%$, and a silty fraction of about $60 \%$. On average, the material has a liquid limit $\left(\mathrm{w}_{\mathrm{L}}\right)$ of $48.9 \%$, a plastic limit $\left(\mathrm{w}_{\mathrm{P}}\right)$ of $27.1 \%$ and, therefore, a plasticity index $\left(\mathrm{I}_{\mathrm{P}}\right)$ of
$21.8 \%$. In the Casagrande's chart, the experimental points lie below the " $A$ " line around $\mathrm{w}_{\mathrm{L}}=50 \%$, thus the material is classified as inorganic silt of medium/high compressibility.

A twin set of samples was tested in this work. The first set of samples were compacted in the laboratory at the optimum value of water content according to Standard Proctor method. The second set of samples were instead retrieved, with the least possible disturbance, from the field embankment. The embankment had been built by compacting soil at the same optimum water content of the Standard Proctor through the use of conventional heavy machinery. It is important to mention, however, that the undisturbed samples were retrieved few years after construction of the embankment and are therefore likely to have experienced at least some wetting/drying cycles between construction and retrieval from the field.

The samples compacted in the laboratory were produced by using soil collected from the embankment at the same depth of the undisturbed samples. This soil was dried in open air and broken down by means of a mechanical grinder. The soil was then compacted at the optimum water content using the Standard Proctor procedure [3].

The initial values of water content $(w)$, specific water volume $\left(\mathrm{v}_{\mathrm{w}}=1+\mathrm{e}_{\mathrm{w}}\right.$ where $\mathrm{e}_{\mathrm{w}}$ is water ratio that is equal to $\left.\mathrm{S}_{\mathrm{r}}{ }^{*} \mathrm{e}\right)$, specific volume $(\mathrm{v})$, degree of saturation $\left(\mathrm{S}_{\mathrm{r}}\right)$ and dry density $\left(\rho_{\mathrm{d}}\right)$ are summarized in Table 1 for all samples tested in this work. The initial letter of the sample name ( $\mathrm{S}$ or $\mathrm{L}$ ) indicates in-situ or laboratory compacted samples while the numbers $(50,100,200$ or $500)$ at the end of the sample name indicates the constant net vertical stress (in $\mathrm{kPa}$ ) at which the water retention test was performed.

Table 1. Initial values of tests.

\begin{tabular}{|c|c|c|c|c|c|}
\hline Test code & $\begin{array}{c}\mathbf{w} \\
\mathbf{( \% )}\end{array}$ & $\mathbf{v}_{\mathbf{w}}$ & $\mathbf{v}$ & $\begin{array}{c}\mathbf{S}_{\mathbf{r}} \\
\mathbf{( \% )}\end{array}$ & $\begin{array}{c}\mathbf{\rho}_{\mathbf{d}} \\
\left(\mathbf{g} / \mathbf{c m}^{\mathbf{3}}\right)\end{array}$ \\
\hline S-E1tvn50 & 31.27 & 1.86 & 1.92 & 93.41 & 1.43 \\
\hline S-E3tvn100 & 30.51 & 1.84 & 1.91 & 92.43 & 1.44 \\
\hline S-E4tvn200 & 27.99 & 1.77 & 1.88 & 88.09 & 1.47 \\
\hline L-E7tvn50 & 20.34 & 1.56 & 1.63 & 88.36 & 1.69 \\
\hline L-E8tvn200 & 20.32 & 1.56 & 1.65 & 85.87 & 1.67 \\
\hline L-E9tvn500 & 19.75 & 1.54 & 1.63 & 86.94 & 1.69 \\
\hline
\end{tabular}

Fig. 2 shows two Standard Proctor curves determined by two different research laboratories (UNINA and UNICAS) together with the points of the samples tested in this work. Fig. 3 shows some grading curves determined on different samples of soil tested.

Prior to imposing any water retention path, each specimen was loaded to a different vertical net stress $\left(\sigma_{\mathrm{v}}\right.$ $\mathrm{u}_{\mathrm{a}}$ ) to investigate the influence of the applied stress, and hence of the deformation, on the retention behaviour. Each test consisted of a drying-wetting cycle with step changes of suction at 5, 10, 20, 50, 100, 200, 300, 400, 


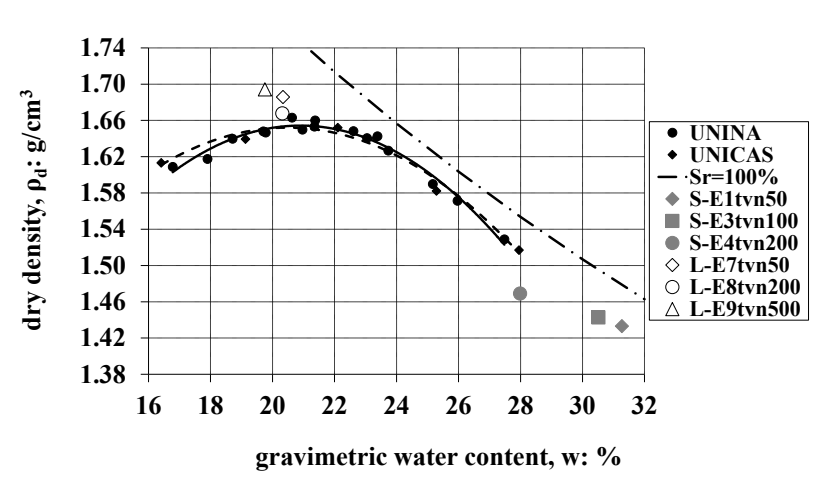

Figure 2. Soil proctor curves and points representative of the samples tested.

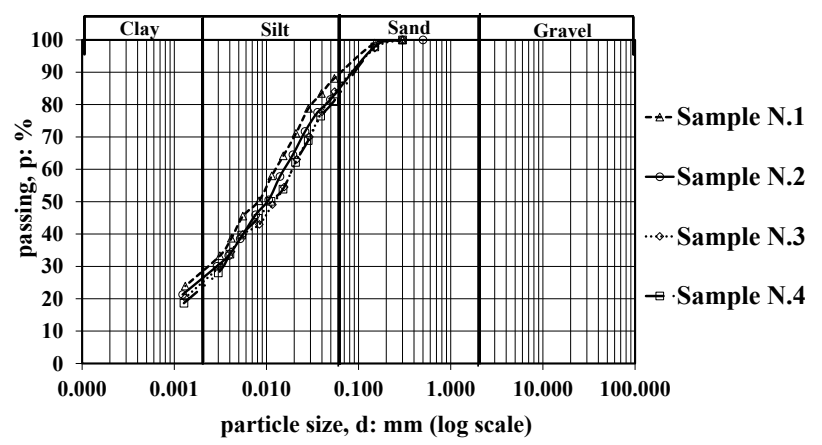

Figure 3. Soil grading curves determined on different samples of tested soil.

600 and $850 \mathrm{kPa}$ (pore air pressure was changed while pore water pressure was maintained constant and equal to $50 \mathrm{kPa})$. An initial equalization stage at a suction of $5 \mathrm{kPa}$ (10 $\mathrm{kPa}$ only for test S-E1tvn50) was followed by a step drying path until a maximum value of suction that was $400 \mathrm{kPa}$ for tests S-E1tvn50, S-E3tvn100, S-E4tvn200, $500 \mathrm{kPa}$ for test L-E7tvn50 and $850 \mathrm{kPa}$ for tests L-E8tvn200, L-E9tvn500. All tests ended with a wetting path from the maximum suction level down to a suction of $5 \mathrm{kPa}(100 \mathrm{kPa}$ only for test S-E1tvn50).

\section{Experimental results}

Figure 4 shows the variation of degree of saturation versus suction for the tests on the in-situ compacted samples.

The slopes of the three drying curves are relatively similar, though a slight dependency on the vertical net stress can be appreciated. This is consistent with the fact that samples subjected to higher stresses and thus higher reduction of void ratio exhibit a smaller variation of degree of saturation for the same suction increment due to smaller pores dimensions.

A significant hydraulic hysteresis is observed upon suction reversal with all wetting paths characterized by similar slopes.

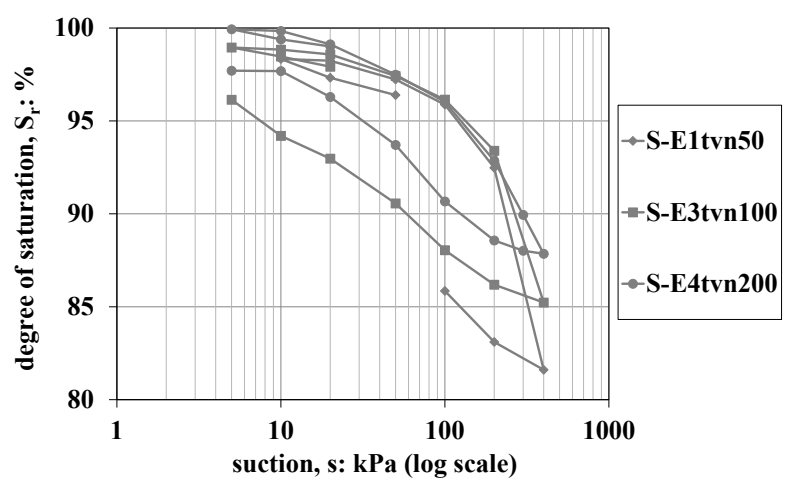

Figure 4. Tests on samples compacted in situ in the $\mathrm{S}_{\mathrm{r}}$ : s plane.

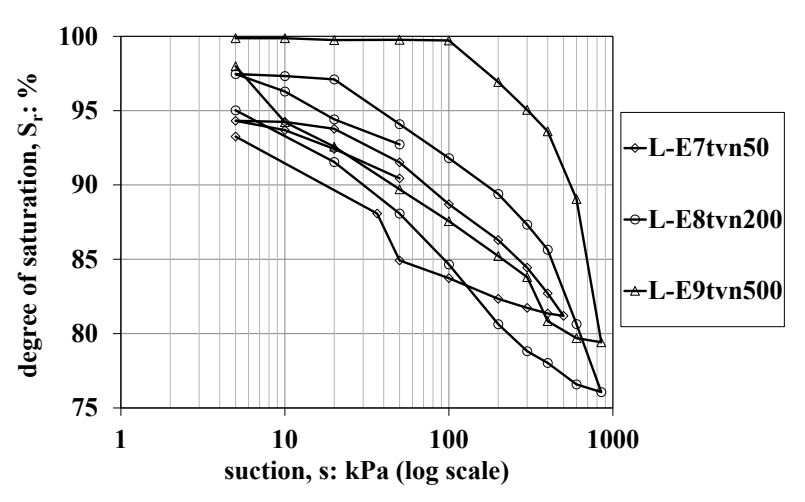

Figure 5. Tests on samples compacted in the laboratory in the $\mathrm{S}_{\mathrm{r}}$ : s plane.

Figure 5 presents the retention curves of the three samples compacted in the laboratory. These tests present larger differences between them compared to the three tests on the samples compacted in-situ. This is probably because the samples compacted in-situ have experienced already several wetting/drying cycles in the field, which have hardened the soil and made it less sensitive to the applied vertical net stress during testing.

An additional reason of such differences could be that the in-situ compacted samples start drying from relatively high values of degree of saturation (above 97.5\%) and are, presumably, on a main drying curve since the very beginning of the drying path. Instead, the laboratory compacted samples start drying from slightly lower

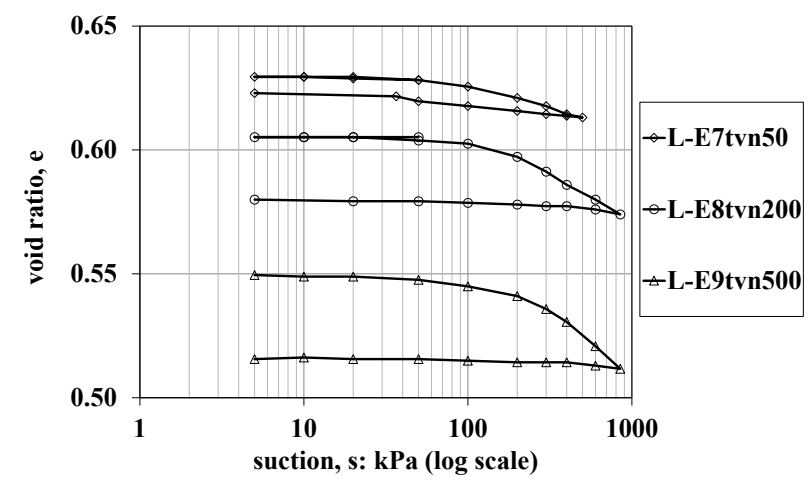

Figure 6. Tests on samples compacted in the laboratory in the e : s plane. 


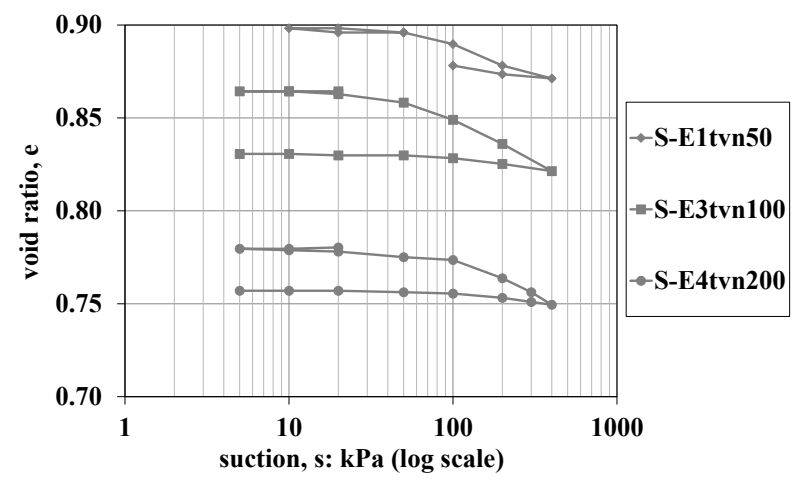

Figure 7. Tests on samples compacted in situ in the e $: \mathrm{s}$ plane.

values of degree of saturation, which means that they are probably on a scanning curve for the first part of the drying path.

Figures 6 and 7 show the variation of void ratio versus suction for the samples compacted in the laboratory and in situ, respectively. A slight dependency of elastic deformation during wetting on the vertical net stress is observed. For both in-situ and laboratory compacted samples, the magnitude of elastic deformation during suction variation increases at decreasing values of vertical net stress. This behaviour seems not to depend on the compaction technique as similar sensitivity of void ratio to suction variation have been observed in the two sets of tests.

Elasto-plastic strains occur during drying paths but their magnitude is not very sensitive to the applied vertical net stress. Different responses are however observed for the samples compacted in situ and in the laboratory with the former samples experiencing larger strains under similar variations of suction.

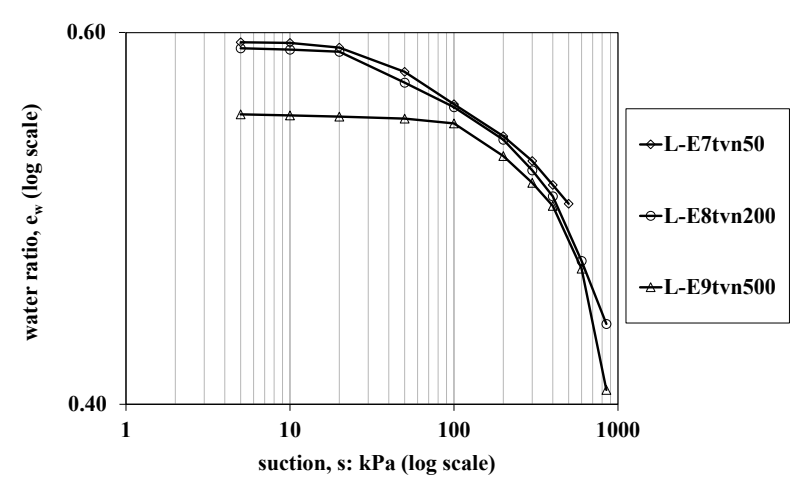

Figure 8. Tests on samples compacted in the laboratory in the $\mathrm{e}_{\mathrm{w}}: \mathrm{s}$ plane.

One interesting aspect emerges when the different drying curves are recast in the $\log _{\mathrm{w}}-\operatorname{logs}$ plane. As suction grows large, the water ratio tends to a linear asymptote that is independent of void ratio and reduces to a unique relationship between water ratio and suction. This can be observed in Figures 8 and 9 where all curves seem to tend to a unique asymptote. The uniqueness of this relationship between water ratio and suction at high suction (and low saturation) has already been

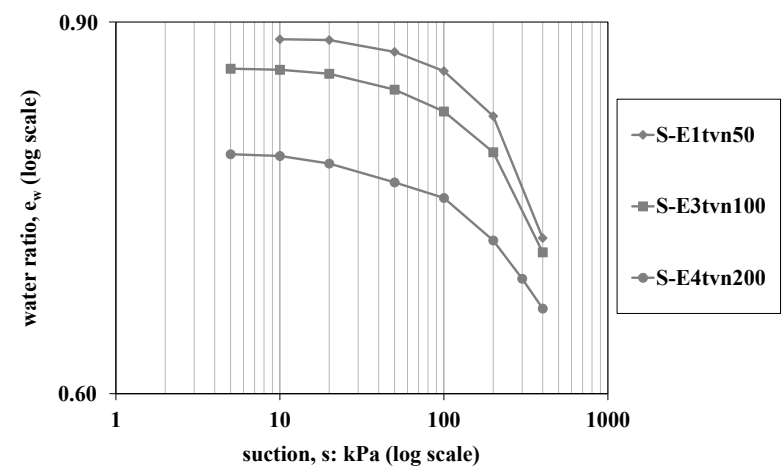

Figure 9. Tests on samples compacted in situ in the $\mathrm{e}_{\mathrm{w}}$ : s plane.

experimentally observed in compacted silts and clays with different degrees of activity [4-6].

The above observations are also in agreement with the retention model proposed by Gallipoli (2012) [7] and Gallipoli et al. (2015) [8], who suggested that any mechanically-induced change of void ratio will only affect the largest pores while leaving the smaller ones almost unchanged. At high suction (and low saturation), water withdraws in the smallest pores so that any mechanically-induced change of void ratio is unable to cause a variation of water ratio. This also means that, as suction grows large, the drying curves at different levels of void ratio will tend towards a unique relationship between water ratio and suction, which is dictated by the retention properties of the smallest pores.

\section{Interpretation of experimental results}

\subsection{Model used}

Experimental results have been interpreted with the water retention model by Gallipoli 2012 [7].

As well known, this water retention model is capable of predicting the hysteretic response of soils during both wetting-drying cycles at constant void ratio and compression-swelling cycles at constant suction. The model formulation is capable of capturing important soil features such as, for example, the influence of hydraulic hysteresis and deformation on the variation of degree of saturation and the dependency of water retention behaviour during compression on previous wettingdrying history. Moreover, during main wetting or main drying at high suction (i.e. at low saturation), the model correctly predicts a "virgin" retention line that uniquely relates water ratio and suction regardless of the current value of void ratio.

In the model two main surfaces, i.e. the main wetting and main drying surfaces, enclose the domain of attainable soil states in the degree of saturation - suction - void ratio space. Inside this domain, the variation of degree of saturation is governed by a reversible scanning law, which describes the transition from one main surface to the other.

From the physical point of view:

- a soil state is assumed to lie on the main drying surface if there is at least one infinitesimal change of suction 
and/or void ratio which causes irreversible drainage of initially flooded pores;

- a soil state is assumed to lie on the main wetting surface if there is at least one infinitesimal change of suction and/or void ratio which causes irreversible flooding of initially drained pores.

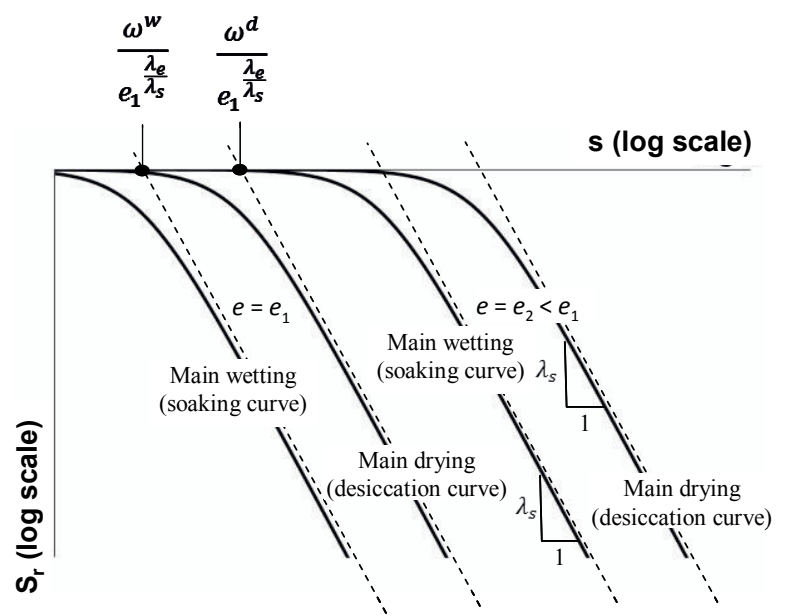

Figure 10. Main hysteretic loops in $S_{\mathrm{r}}$ : s plane corresponding to different $\mathrm{e}_{1}$ and $\mathrm{e}_{2}$ (with $\mathrm{e}_{1}>\mathrm{e}_{2}$ )

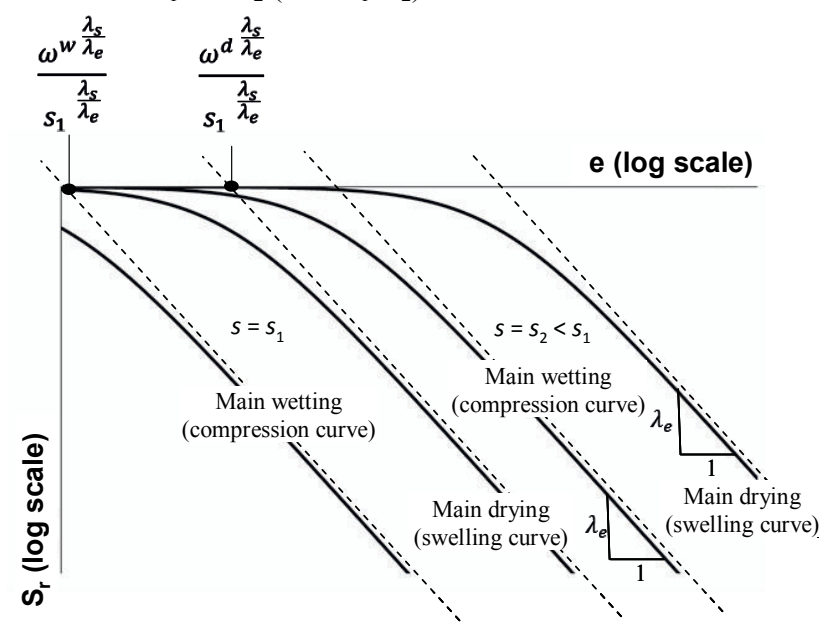

Figure 11. Main hysteretic loops in $S_{\mathrm{r}}$ : e plane corresponding to different $s_{1}$ and $s_{2}$ (with $s_{1}>s_{2}$ )

Some terminology is introduced to refer to the crosssections of the main drying and wetting surface with planes at constant e $\left(\log S_{\mathrm{r}}-\log \mathrm{s}\right.$ plane, figure 10$)$ and constant $\mathrm{s}\left(\log \mathrm{S}_{\mathrm{r}}-\log\right.$ e plane, figure 11). In particular, the intersection of main (wetting or drying) surface with generic $\log \mathrm{S}_{\mathrm{r}}-\log \mathrm{s}$ plane at constant e generates:

- a Soaking curve (in case of main wetting surface);

- a Desiccation curve (in case of main drying surface).

The intersection of a main (wetting or drying) surface with generic $\log \mathrm{S}_{\mathrm{r}}-\log$ e plane at constant $\mathrm{s}$ generates:

- a Compression curve (in case of main wetting surface);

- a Swelling curve (in case of drying surface).

The two main wetting and the main drying surfaces are defined by a total of 8 parameters ( 4 for each surface):

- main drying: $\left\{\lambda_{\mathrm{sd}} \lambda_{\mathrm{ed}} \omega_{\mathrm{d}} \mathrm{m}_{\mathrm{d}}\right\}$

- main wetting $\left\{\lambda_{\text {sw }} \lambda_{\text {ew }} \omega_{\mathrm{w}} \mathrm{m}_{\mathrm{w}}\right\}$ that:

The number of parameters is reduced by assuming
- identical asymptotic slopes for main drying and wetting surfaces in $\log \mathrm{Sr}-\log$ s plane:

$$
\lambda_{\mathrm{sd}}=\lambda_{\mathrm{sw}}=\lambda_{\mathrm{s}} \quad \text { or } \quad \mathrm{m}_{\mathrm{d}} * \mathrm{n}_{\mathrm{d}}=\mathrm{m}_{\mathrm{w}} * \mathrm{n}_{\mathrm{w}}
$$

- identical asymptotic slopes for main drying and wetting surfaces in $\log \mathrm{Sr}$ - log e plane:

$$
\lambda_{\mathrm{ed}}=\lambda_{\mathrm{ew}}=\lambda_{\mathrm{e}} \text { or } \psi_{\mathrm{d}} * \mathrm{~m}_{\mathrm{d}} * \mathrm{n}_{\mathrm{d}}=\psi_{\mathrm{w}} * \mathrm{~m}_{\mathrm{w}} * \mathrm{n}_{\mathrm{w}}
$$

- identical shapes for main drying and wetting surfaces when departing from asymptotic planes:

$$
\mathrm{m}_{\mathrm{d}}=\mathrm{m}_{\mathrm{w}}=\mathrm{m}
$$

The above assumptions imply, as a consequence :

$$
\begin{gathered}
\mathrm{n}_{\mathrm{d}}=\mathrm{n}_{\mathrm{w}}=\mathrm{n} \\
\psi_{\mathrm{d}}=\psi_{\mathrm{w}}=\psi
\end{gathered}
$$

A family of surfaces scanning the space between the two main drying and wetting surfaces is also defined. If a soil path on the main drying surface is reversed, the soil state departs from the main drying surface, moves along the adjacent scanning surface, spanning across the space between the two main surfaces, until it joins the opposite main wetting surface. Similarly, if a soil path on the main wetting surface is reversed, the soil state departs from the main wetting surface, moves along the adjacent scanning surface, spanning across the space between the two main surfaces, until it joins the opposite main drying surface. Soil behaviour is assumed to be reversible along a scanning surface.

\subsection{Model calibration}

Experimental data shown in section 4 have been interpreted with the model by Gallipoli 2012 [7] described in the previous section. Only data relative to the drying paths have been modelled as calibration of main surfaces is more crucial, with respect to the scanning surfaces, for an appropriate prediction of soil behaviour in earth structures for engineering purposes.

The first hypothesis made is that the experimental data relative to the drying paths lie on the main drying. This is a reasonable assumption because, for each tested sample, after the first wetting stage at $5 \mathrm{kPa}$ of suction, degree of saturation is close to $100 \%$, and in any case lower than $94.5 \%$.

The equation of main drying proposed in the model is:

$$
\mathrm{S}_{\mathrm{r}}=\left(1+\left(\frac{\mathrm{e}^{\Psi_{* s}}}{\omega}\right)^{\mathrm{n}}\right)^{-\mathrm{m}}
$$

As proposed by the model, as suction grows large the water ratio tends to a log-planar asymptote whose expression in the model is given by:

$$
\begin{gathered}
\log \mathrm{e}_{\mathrm{w}}=\mathrm{m} * \mathrm{n} * \log \omega-(\mathrm{m} * \mathrm{n} * \Psi-1) * \\
* \log \mathrm{e}-\mathrm{m} * \mathrm{n} * \log \mathrm{S}
\end{gathered}
$$

Assuming the uniqueness of the relationship between water ratio and suction at high suction/low saturation 
levels, as observed in the literature (see section 4), the product $\mathrm{m} * \mathrm{n} * \psi$ is equal to 1 . In this hypothesis, in fact, the log-planar asymptote becomes independent of void ratio and reduces to a unique relationship between water ratio and suction.

Indeed, a calibration of the main wetting surface performed by Gallipoli et al. (2003b) [9] for a different material (i.e. the compacted Speswhite kaolin tested by Sivakumar (1993) [10]) yielded a similar value of 1.1 for the parameters product $m * n * \psi$. It is also interesting to note that, by following an alternative modelling approach, Sheng (2010) [11] advocated a choice of parameter values that satisfies the condition $m * n * \psi=1$ to ensure consistency with the intrinsic phase relationship in the model by Gallipoli et al. (2003b) [9]. Moreover, inspection of figures 8 and 9 indicates that it is reasonable to assume the product $\mathrm{m} * \mathrm{n} * \psi$ equal to 1 for the tested soil.

Under the above assumption, the number of independent parameters defining the main drying surface reduces from four to three, namely $(\omega, \mathrm{m}, \mathrm{n})$. Indeed $\psi$ is taken equal to $1 /\left(\mathrm{m}^{*} \mathrm{n}\right)$ and it is possible to rewrite equation (1) as:

$$
\mathrm{Sr}=\left(1+\left(\frac{\mathrm{e}^{\frac{1}{\mathrm{~m} * \mathrm{n}} * \mathrm{~s}}}{\omega}\right)^{\mathrm{n}}\right)^{-\mathrm{m}}
$$

Values of $\omega, \mathrm{m}$ and $\mathrm{n}$ have been determined by fitting experimental points of drying paths with equation 8 .

\subsection{Results interpretation}

Two separate parameters determination have been done for the laboratory and in-situ compacted samples.

For each set of samples the model parameters defining the main drying curve have been determined on the basis of experimental points of drying paths relative to two of the three tests performed.

The parameters determination done for the laboratory compacted samples refers to the tests performed under a vertical net stress of 200 and $500 \mathrm{kPa}$. The above choice has been made on the basis of the higher degree of saturation at the starting of the drying and therefore the more confidence for that data to be on a main surface.

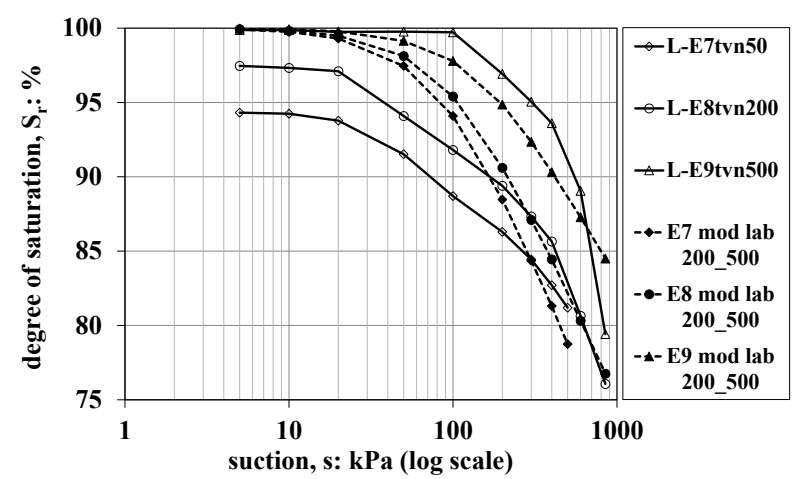

Figure 12. Tests on samples compacted in the laboratory in the $\mathrm{S}_{\mathrm{r}}$ : s plane and model predictions with calibration done using tests L-E8tvn200 and L-E9tvn500.
In figure 12 experimental data relative to soil compacted in the laboratory together with model predictions are shown. The model seems not to predict particularly well the soil behaviour, especially for the curve not used in the fitting process. In reality, part of the misprediction could be due to the fact that degree of saturation at the starting of the drying is not particularly high and therefore the experimental data points could be not on a main surface in the first part of the test.

The model parameters and the starting conditions obtained from calibration have been then used to simulate the behaviour of samples compacted in situ (Fig. 13). This is because, in common engineering practice, data available for modelling are those of the soil compacted in the laboratory and soil behaviour during the earth structures lifecycle is predicted on this basis.

The model seem to predict reasonably well the position of the main drying surface and the sensitivity to the applied stress, thus to the current void ratio, but not the slope.

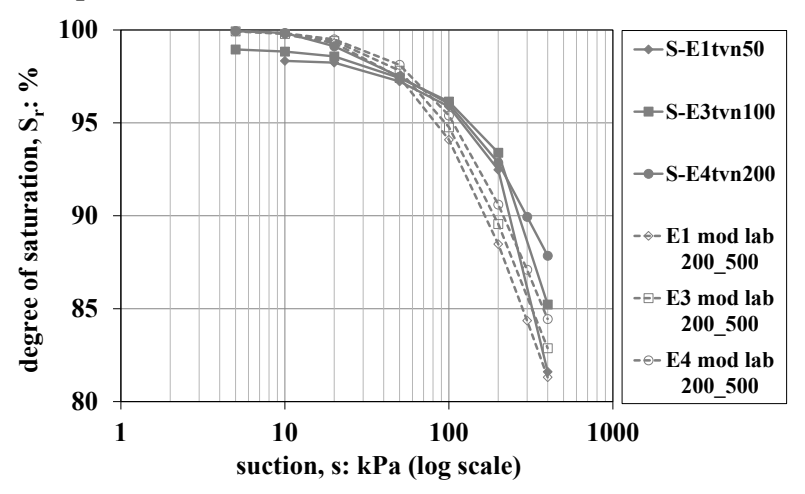

Figure 13. Tests on samples compacted in situ in the $S_{r}: s$ plane and model predictions with calibration done using tests LE8tvn200 and L-E9tvn500.

In order to investigate whether the weakness is in the model or in the difference in the compaction procedures, the model has been also calibrated with data relative to the tests on samples compacted in situ.

The experimental points chosen for the fitting procedure are those of tests performed under a vertical net stress of 50 and $200 \mathrm{kPa}$. In figure 14 experimental data relative to soil compacted in situ together with model predictions are shown.

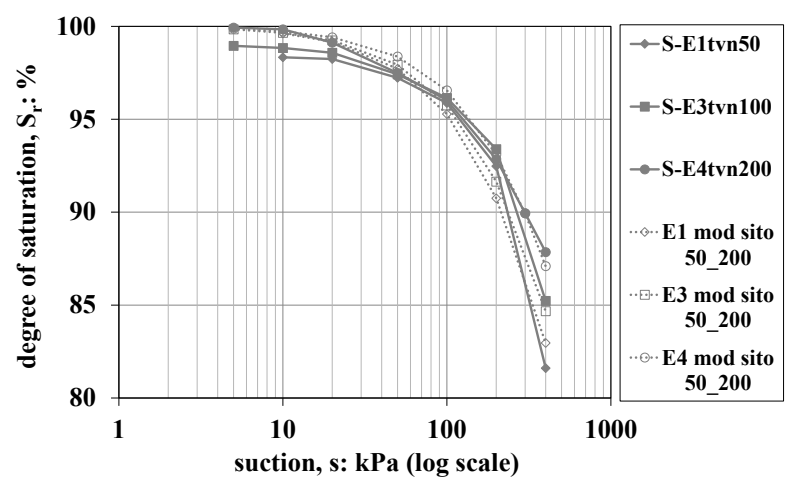

Figure 14. Tests on samples compacted in situ in the $S_{r}: s$ plane and model predictions with calibration done using tests SE1tvn50 and S-E4tvn200. 
The model seems to predict reasonably well the experimental behaviour in terms of position, slope and sensitivity to applied stress, even for the curve not used in the fitting process.

The good model prediction can be attributable to the consistency of data of different tests and to the very high degree of saturation at the starting of each drying path.

\section{Concluding remarks}

The present work has investigated the influence of compaction procedure on the water retention behavior of a clayey silt. With this aim, a twin set of samples has been tested. Samples compacted in the laboratory at optimum Proctor standard and samples compacted in situ by conventional heavy machinery.

Samples compacted in situ show an higher degree of saturation and a lower dry density. This could be due to the stress paths experienced from the time of the embankment construction to the time of retrieval and/or to an under compaction and/or to a compaction at a too high water content. If the first is the case, the soil compacted in situ and in the laboratory should still have the same texture as the stress paths modify the status but not the fabric of the soil and therefore its behaviour.

Tests on samples compacted in the laboratory present larger differences between them compared to the tests on the samples compacted in-situ. This is probably because the samples compacted in-situ have experienced already several wetting/drying cycles in the field, or because the in-situ compacted samples start drying from relatively high values of degree of saturation in comparison to laboratory compacted ones and are therefore on a main drying curve since the very beginning of the drying path. Elasto-plastic strains occur during drying paths but their magnitude is not very sensitive to the applied vertical net stress. Different responses are however observed for the samples compacted in situ and in the laboratory with the former samples experiencing larger strains under similar variations of suction.

Experimental data relative to the drying paths of laboratory compacted samples have been interpreted with the model by Gallipoli 2012. The model parameters and the starting conditions obtained from calibration have been then used to simulate the behaviour of samples compacted in situ as it is done in common engineering practice where only data on laboratory compacted samples are available for design of earth structures. The model seems to predict reasonably the position of the main drying surface and its sensitivity to the applied stress, thus to the current void ratio, but not its slope. In order to investigate whether the weakness is in the model or in the dissimilar soil behaviour when compacted with different procedures, the model has been calibrated with data relative to the tests on samples compacted in situ. The model seems to predict reasonably the soil behaviour in terms of position, slope and sensitivity to applied stress.

In conclusion a dissimilar behaviour has been observed on the two sets of samples. Caution should be therefore used in common engineering practice when assuming that properties of earth fills are similar to those of laboratory compacted samples under the same prescriptions. This is for two reasons: the first is that control procedures of in situ compaction is not always accurate and could produce compaction at a different water content and different energy with respect to the prescriptions. The second reason is that different compaction procedures could induce different soil fabrics. Both the above reasons could cause the dissimilar behaviour observed in the present work.

\section{Acknowledgments}

The contribution of the European Commission via the Career Integration Grant SAFES (Service Assessment and Failure of Earth Structures), contract n. PCIG09-GA2011-293727, is gratefully acknowledged.

\section{References}

1. S.J. Wheeler, V. Sivakumar. Influence of compaction procedure on the mechanical behaviour of an unsaturated compacted clay. Part 1: wetting and isotropic compression. (Géotechnique 50, 4, 2000).

2. S.J. Wheeler, V. Sivakumar. Influence of compaction procedure on the mechanical behaviour of an unsaturated compacted clay. Part 2: shearing and constitutive modelling. (Géotechnique 50, 4, 2000).

3. ASTM 2005. D0698-00 AE01 test method for laboratory compaction characteristics of soil using standard effort (12 $\left.400 \mathrm{ft} \cdot \mathrm{lbf} / \mathrm{ft}^{3}\left(600 \mathrm{kN} \cdot \mathrm{m} / \mathrm{m}^{3}\right)\right)$. Vol. 04.08. In ASTM Book of Standards. ASTM, Philadelphia, Penn.

4. E. Romero, A. Gens, A. Lloret. Water permeability, water retention and microstructure of unsaturated Boom clay. (Eng. Geol. 54, 117-127, 1999).

5. E. Romero, J. Vaunat. Retention curves of deformable clays. (Proc. Int. Workshop on Unsaturated Soils, Trento, Italy, 91-106, 2000).

6. E. Romero, G. Della Vecchia, C. Jommi. An insight into the water retention properties of compacted clayey soils. (Géotechnique 61, 4, 2011).

7. D. Gallipoli. A hysteretic soil-water retention model accounting for cyclic variations of suction and void ratio. (Géotechnique 62, 7, 2012).

http://dx.doi.org/10.1680/geot.11.P.007.

8. D. Gallipoli, A.W. Bruno, F. D’Onza, C. Mancuso. A bounding surface hysteretic water retention model for deformable soils. (Géotechnique 65, 10, 2015). http://dx.doi.org/10.1680/geot.14.P.118.

9. D. Gallipoli, S.J. Wheeler, M. Karstunen. Modelling the variation of degree of saturation in a deformable unsaturated soil. (Géotechnique 53, 1, 2003b). http://dx.doi.org/10.1680/geot.2003.53.1.105.

10. V. Sivakumar. A critical state framework for unsaturated soils. (Ph.D. Thesis, U. Sheffield, U.K., 1993).

11. D. Sheng. Constitutive modelling of unsaturated soils: Discussion of fundamental principles. (Proc. 5 th Int. Conference on Unsaturated Soils, Barcelona, Spain, 1, 2010). 